\title{
COMO CONSULTAR A RELAÇÃO DE PROGRAMAS INSCRITOS
}

\section{Forma de apresentação das iniciativas adotada nesta publicação}

A apresentação dos 981 programas, projetos ou atividades inscritos no Ciclo de Premiação 2002 do Programa GESTÃO PÚBLICA E CIDADANIA está ordenada, nesta publicação, a partir das áreas e sub-áreas de atuação governamental. É preciso deixar claro que a inserção de tais programas nas áreas propostas admite diversas possibilidades, cabendo aos responsáveis pela inscrição sua própria classificação. O Programa GESTÃO PÚBLICA E CIDADANIA procurou classificar apenas as inscrições que apresentavam informações incompletas ou insuficientes. Portanto, é possivel que sejam encontrados programas, projetos ou atividades típicos de determinada área de ação governamental (ex.: educação, finanças e orçamento público etc.) em áreas correlatas (ex.: criança e adolescente, participação popular etc.). Neste sentido, é conveniente que os interessados em determinada área consultem também outras, para que se possa obter uma visão mais abrangente das inscrições no Ciclo de Premiação 2002.

Dentro de cada área, os programas, projetos ou atividades estão ordenados numericamente, de acordo com a data de chegada dos questionários respondidos. A apresentação de cada programa, projeto ou atividade inclui o rol de informações apresentado no quadro a seguir.

CIDADANIA E DIREITOS HUMANOS - MINORIAS

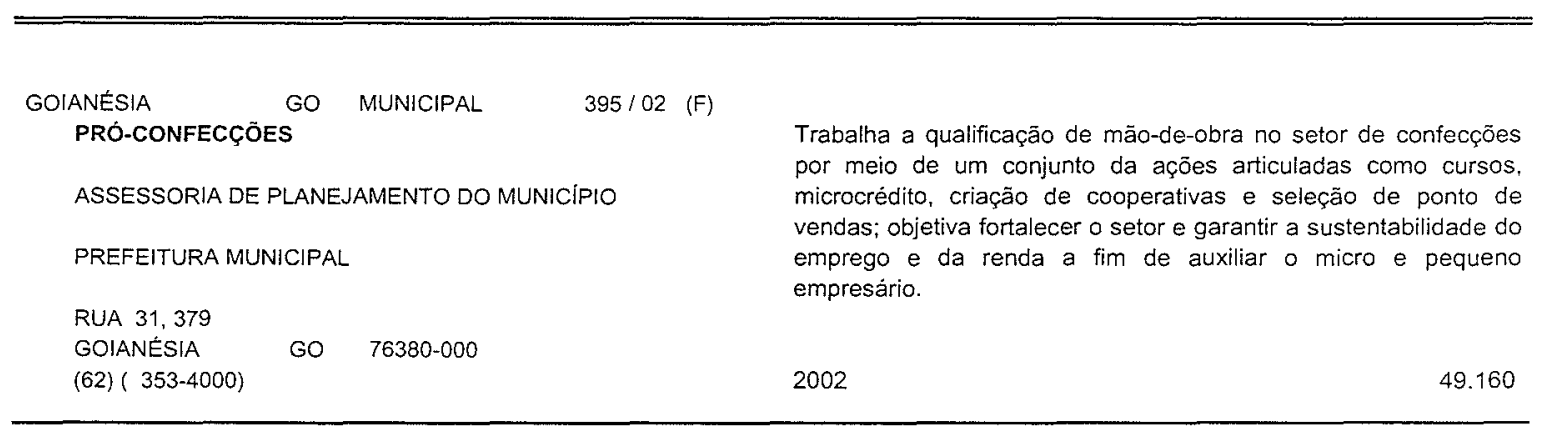


Informações relațivas aos programas, projetos e atividades apresentadas nesta publicação

\begin{tabular}{|c|c|}
\hline \multicolumn{2}{|c|}{ lado esquerdo: } \\
\hline $\begin{array}{l}1^{\circ} \\
\text { parágrafo }\end{array}$ & $\begin{array}{l}\text { - Nome do Estado, município ou área indigena; sigla da unidade da federação; níve } \\
\text { de governo do órgão responsável pela inscrição do programa, projeto ou atividade. } \\
\text { - Ao lado direito, está apresentado o número da inscrição no Ciclo de Premiação } 2002 \\
\text { facilitando a localização no Banco de Dados em caso de interesse de informações } \\
\text { mais detalhadas. } \\
\text { - As consoantes "S", "PF" e "F" que aparecem entre parênteses após o número de } \\
\text { inscrição sinalizam os programas, projetos ou atividades classificados } \\
\text { respectivamente como semifinalistas, pré-finalistas e finalistas no Ciclo de Premiação } \\
2002 \text { (para uma sintese do processo de indicação para premiação ver p. 195). Nesta } \\
\text { edição não será discriminado os programas com classificados como destaque dos } \\
\text { finalistas, pois o livro foi finalizado antes da premiação final. Quem tiver interesse em } \\
\text { ter conhecimento sobre os cinco programas destaques do ano 2002, podem acessar } \\
\text { o banco de dados eletrônico no nosso site na Internet. }\end{array}$ \\
\hline $\begin{array}{l}2^{\circ} \\
\text { parágrafo }\end{array}$ & $\begin{array}{l}\text { Nome do programa, projeto ou atividade. Em casos de nomes muito longos, por } \\
\text { motivo de padronização editorial, foram feitas pequenas alterações sem prejuizo do } \\
\text { significado expresso pelo nome original. }\end{array}$ \\
\hline $\begin{array}{l}3^{\circ} \\
\text { parágrafo }\end{array}$ & Nome do órgão público responsável pela inscrição. \\
\hline $\begin{array}{l}4^{\circ} \text { ao } 7^{\circ} \\
\text { parágrafos }\end{array}$ & $\begin{array}{l}\text { - Dados cadastrais da instituição executora, constando: nome; endereço completo } \\
\text { para correspondência; telefone (número à esquerda); e, quando disponivel, o fax } \\
\text { (número à direita). }\end{array}$ \\
\hline \multicolumn{2}{|l|}{ lado direito: } \\
\hline $\begin{array}{l}\text { parágrafo } \\
\text { superior }\end{array}$ & $\begin{array}{l}\text { - Descrição sintética do programa, projeto ou atividade, elaborada a partir de resumo } \\
\text { escrito pelo responsável na ficha de inscrição. }\end{array}$ \\
\hline $\begin{array}{l}\text { parágrafo } \\
\text { inferior }\end{array}$ & $\begin{array}{l}\text { - No lado esquerdo, ano de inicio do programa, projeto ou atividade. } \\
\text { - No lado direito, número de habitantes da localidade onde o programa, projeto ou } \\
\text { atividade é desenvolvido, segundo dados da Contagem Populacional de } 1996 \text {. }\end{array}$ \\
\hline
\end{tabular}




\section{Índice remissivo}

Como instrumento auxiliar de consulta do material aqui publicado foi montado um índice Remissivo no qual os 981 programas, projetos e atividades inscritos no Ciclo de Premiação 2002 estão indexados a partir do município ou Estado aos quais estão vinculados os órgãos responsáveis pelas inscrições. Programas, projetos ou atividades estaduais de âmbito municipal estão indexados pela cidade onde são desenvolvidos, da mesma forma que os sob responsabilidade de organizações próprias dos povos indígenas.

Adicionalmente, o índice subdivide-se em outras partes, permitindo a localização de informações de acordo com outros critérios de entrada dos dados. O quadro abaixo, utilizando o já citado exemplo, ilustra as diversas formas pelas quais um mesmo programa pode ser localizado a partir do índice.

\begin{tabular}{|c|c|}
\hline critério de entrada no índice remissivo & exemplo do formato encontrado \\
\hline 1. áreas de ação governamental & - Criança e adolescente - 130-148 \\
\hline $\begin{array}{l}\text { 2. destaques, finalistas, pré-finalistas e } \\
\text { semifinalistas segundo o local e nível } \\
\text { de governo ou âmbito do programa }\end{array}$ & $\begin{array}{l}\text { Finalistas } \\
\quad \text { Fortaleza, CE, nível estadual - } 113\end{array}$ \\
\hline $\begin{array}{l}\text { 3. nivel de governo ou âmbito } \\
\text { (programas interestaduais, estaduais, } \\
\text { intermunicipais, municipais, e de } \\
\text { organizações próprias dos povos } \\
\text { indigenas) segundo as unidades da } \\
\text { federação }\end{array}$ & $\begin{array}{l}\text { Nivel Estadual } \\
\quad \text { Amapá }-65,153,160,162,164,168,169 \\
\quad 170,178\end{array}$ \\
\hline $\begin{array}{l}\text { 4. unidades da federação e nível de } \\
\text { governo ou âmbito do programa } \\
\text { segundo a localidade onde são } \\
\text { desenvolvidos }\end{array}$ & $\begin{array}{l}\text { São Paulo, nível municipal } \\
\text { São José dos Campos - } 31,34,36,39,43 \text {, } \\
\quad 47,50,61,97\end{array}$ \\
\hline $\begin{array}{l}\text { 5. municipios ou Estados e nivel de } \\
\text { governo ou âmbito segundo os nomes } \\
\text { dos programas inscritos }\end{array}$ & $\begin{array}{l}\text { Videira, SC, nível municipal } \\
\text { Animadores Culturais - } 104 \\
\text { Música e Cidadania - } 104\end{array}$ \\
\hline
\end{tabular}

Nos casos em que constam de uma única página da publicação dois ou mais programas indexados pela mesma referência, a informação referente ao número da página, onde estes programas estão localizados, vem acrescida, entre parênteses, do número de programas a que a informação se refere. 


\section{Siglas e abreviaturas adotadas}

Por motivo de padronização editorial, foram adotadas algumas siglas e abreviaturas, indicados a seguir. Siglas das unidades da federação e aquelas originalmente constantes nos próprios nomes dos programas, projetos e atividades, não estão ai incluídas. 


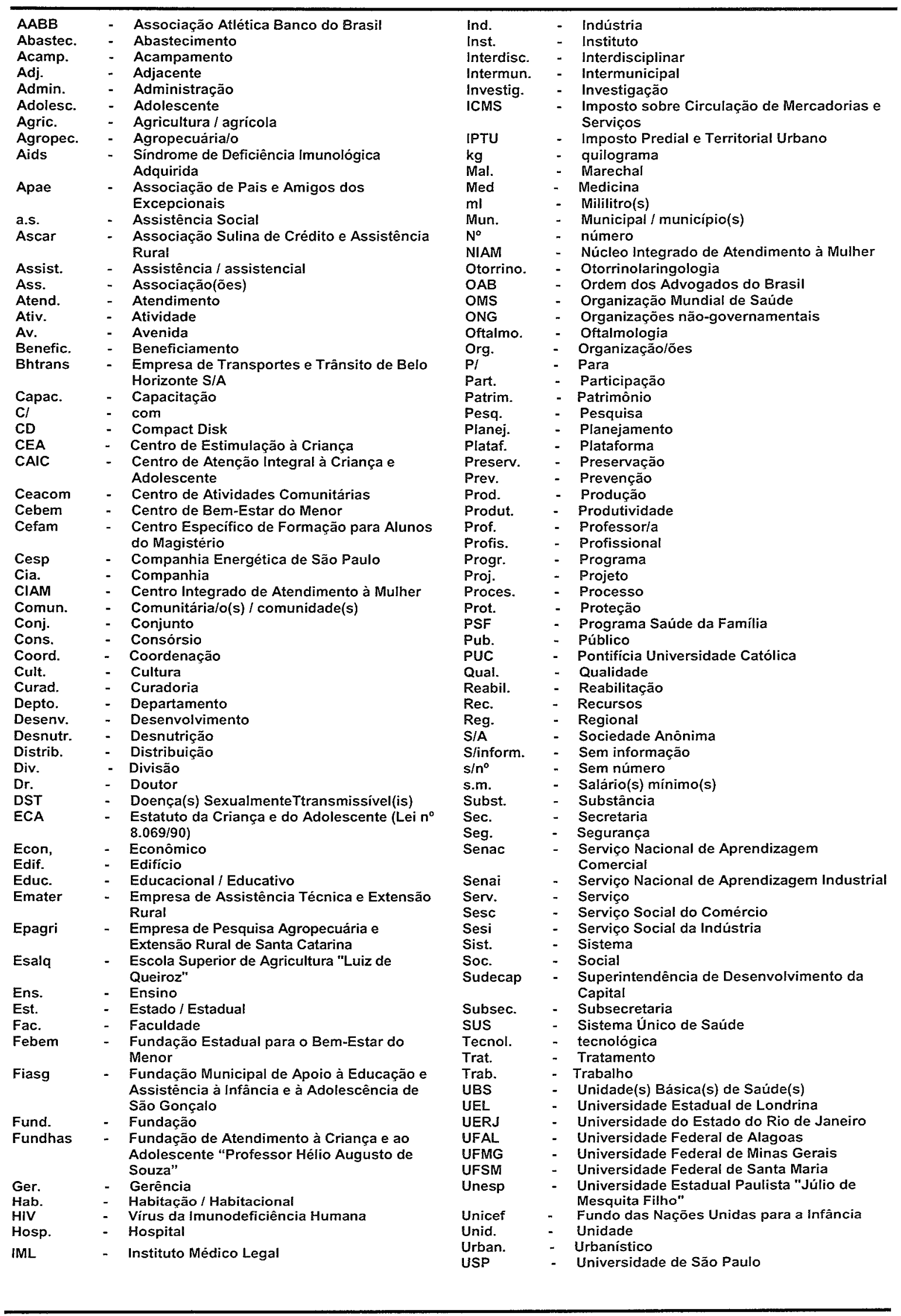


